\title{
Patient Treated with Sub -Mental Intubation for Maxillofacial Trauma
}

Lotfi Bibiche $^{1 *}$, Ayoub Maaroufi ${ }^{1}$, Jawad Laoutid ${ }^{2}$, Nabil Jbili ${ }^{1}$, Abdellatif Diai ${ }^{1}$, Nourdine Jebbar ${ }^{1}$, Kaissi Jaber ${ }^{1}$, Hicham Kechna ${ }^{2}$

${ }^{1}$ MD. Anesthetic, Military Hospital Moulay Ismail Meknes, Faculty of Medicine and Pharmacy of Fez, Sidi Mohamed Ben Abdellah University Fes, Morocco

${ }^{2}$ Professor of Anesthesia Reanimation, Military Hospital Moulay Ismail Meknes, Faculty of Medicine and Pharmacy of Fez, Sidi Mohamed Ben Abdellah University Fes, Morocco

Maxillofacial trauma is frequent and affects a young population. The upper airway intubation technique for intraoperative ventilation is problematic in patients with a fracture of the ethmino-nasal axis associated with a maxillary fracture with occlusal impact. In fact, orotracheal intubation does not allow control of occlusion and the nasotracheal route causes reduction of centro-facial fractures. In these cases, the tracheostomy or Submental intubation (ISM) is a ventilation modality to consider. However, a tracheostomy has a high potential complication rate and in many patients an alternative to oral airways is not needed beyond the perioperative period. Which makes sub-mental intubation an excellent alternative to operate on this type of patient.

Keywords: Submental intubation, Maxillofacial trauma, Airways, Anesthesia.

Copyright @ 2020: This is an open-access article distributed under the terms of the Creative Commons Attribution license which permits unrestricted use, distribution, and reproduction in any medium for non-commercial use (NonCommercial, or CC-BY-NC) provided the original author and source are credited.

\section{INTRODUCTION}

Difficulties in intubation and airway management during maxillofacial trauma constitute a daily challenge for the anesthetist and the maxillofacial surgeon [1]. These traumas are mainly caused by assault, road accidents, accident during a sporting activity. [1] The classic oro - or nasotracheal intubation techniques for the surgical management of these traumas can pose certain difficulties. Indeed, orotracheal intubation does not allow maxillofacial blockage.-mandibular to restore the dental articulation and allow the consolidation of the mandibular fracture. As well as nasotracheal intubation is contraindicated when facial fractures affect the nasal pyramid or radiate to the base of the skull. In these cases, a tracheostomy is usually performed. This invasive procedure carries a significant risk of iatrogenic complications [2].

Anesthesia-resuscitation team and maxillofacial surgeons may opt for intubation submentale (ISM) which leaves a wide access to the oral cavity and the nasal area while avoiding the use of tracheotomy.

\section{Observation}

We report the case of a 32-year-old patient (ASA $1,85 \mathrm{~kg}, 175 \mathrm{~cm}$ ) victim of maxillofacial trauma, presenting a slightly displaced right para-median mandibular fracture associated with fractures of the anterior and posterior walls of the maxillary sinuses with hemosinus as well as a clean bone fracture of the nose. One-step surgical management with completion of a sub-mental intubation is decided. After induction, the patient was intubated by mouth with a probe armed Mallinckrodt (Chesterfield, UK) diameter $7.5 \mathrm{~mm}$. The first chirurgical sub-mental $2 \mathrm{~cm}$ was achieved. The skin incision was made on the right $2 \mathrm{~cm}$ from the mandibular basilar border behind the mylohyoid muscle, taking care not to injure the Wharton's canal and the lingual vessels and nerves. The same armed probe was then bent and introduced by its proximal end through the opening created, from the oral cavity to the sub-mental region, to connect it to the ventilatory circuit with a symmetrical pulmonary auscultation before ensuring its fixation by a thread to the seed coat under the chin (Fig 1 and 2). The entire procedure was performed in 6 minutes and the patient was disconnected from the ventilator for 30 seconds. There was no desaturation. At the end of the operation, the lead fixing wire was cut and its connector disconnected before recovering by simple traction its proximal end in the oral cavity to put it back in the orotracheal position and bipulmonary ventilation was checked. The incision sub -mentale was sutured. The patient was extubated without any particular problem. 
The patient was seen remotely, his scar is not visible in the frontal view and the fracture management was optimal.

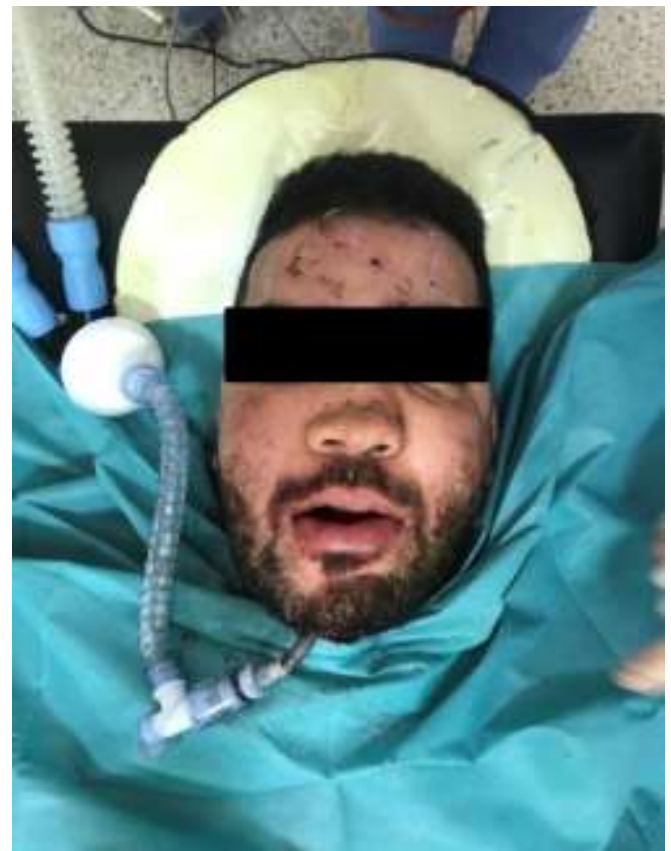

Fig-1: Sub-mental intubation in a patient with maxillofacial trauma.

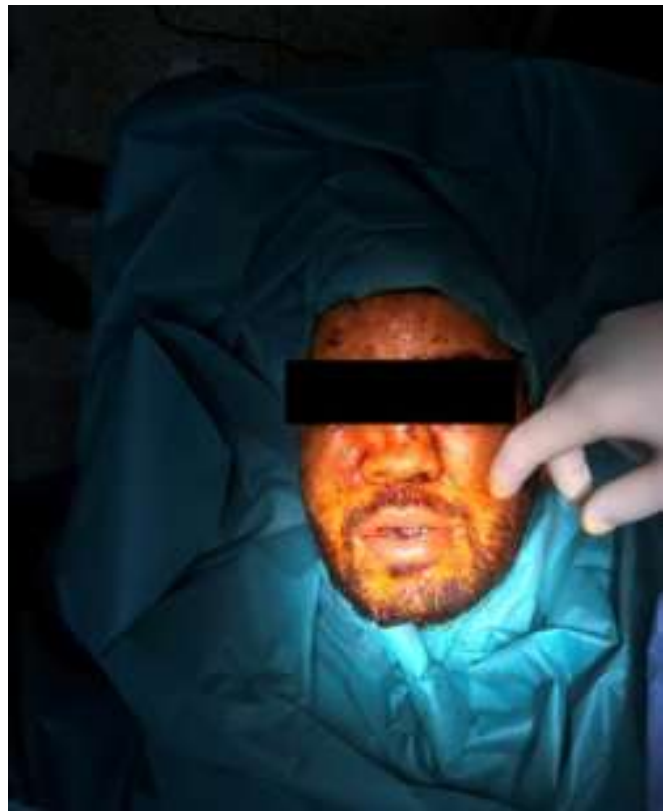

Fig-2: Release of the operative site after sub-mental intubation

\section{DISCUSSION}

Managing the airways for patients with panfacial fractures, requiring both upper airways and dental articulation control, is a real challenge.

Nasotracheal intubation is contraindicated in cases of maxillofacial trauma due to potential complications such as the passage of the tube intracranially (in case of skull base fractures), meningitis, sinusitis and sepsis [3, 4].
Orotracheal intubation allows reduction and internal fixation of fractures but not joint blockage [5], thus hindering the consolidation of the mandibular fracture.

ISM combines the advantages of nasotracheal intubation and those of orotracheal intubation by allowing maxillo- mandibular blockage and access to the nasal pyramid $[5,6]$. It also avoids the risks of tracheostomy such as tracheal stenosis, secondary bleeding wound to the neck vessels or thyroid, emphysema, recurrent laryngeal nerve injury, fistula oeso -trachéale, and tracheomalacia. The average time to perform a tracheostomy is 40 minutes for the open approach [7] while it is 5 minutes for the ISM [8].

ISM is an interesting alternative to tracheostomy in maxillofacial trauma, first described in 1986 by Hernandez Altemir [9]. Other indications are now possible for the application of this technique, such as carcinological surgery of the base of the skull by the endo- oral trans maxillary route for neurosurgeons [10]. For orthognathic surgery (bi-maxillary or sagittal osteotomy with associated rhinoplasty), a study reported a better appreciation by the surgeon of the soft tissues (lip and nose) without the mechanical constraints exerted by the nasal intubation tube $[11,12]$. In plastic surgery for certain nasolabial reconstructions (NOMA, nasolabial clefts) [13]. In oral surgery with nasotracheal intubation impossible, this is the case with congenital or acquired malformations such as septal deviation, polyposis or narrow nasal canals.

The problems with the practice of ISM are bronchial obstruction by mobilization of the probe, lesion of the tube or connector, the accident of extubation. They can be prevented by a good knowledge of the technique. In case of doubt about the correct positioning of the probe, it is possible to carry out a fibroscopic control .

The cons-indications of this technique are the acute infection submental, blood dyscrasias disorders, anatomy laryngeal -trachéale amended, or the need for repeated operations or prolonged intubation where tracheotomy finds its place (gunshot wounds, neurosurgical injuries, chest trauma) [14, 3,15,16 ].

By referring to the experiences of the authors and the current literature, ISM appears to be a safe technique, simple to perform, not very demanding and with low morbidity.

It should be favored whenever the indication occurs. ISM seems to be a reliable, simple and quick learning technique.

However, it requires cooperation between an anesthetist and a trained maxillofacial surgeon. It also avoids a tracheotomy for patients. 
Finally, ISM has a low incidence of intraoperative and postoperative complications.

\section{REFERENCE}

1. Perbet P, Wallet F, Le Manach F, Chaine A, Langeron $\mathrm{O}$. Orotracheal intubation, then transient sub-mental airway approach for emergency maxillofacial trauma surgery. Ann Fr Anesth Reanim. 2009; 28: 604-605.

2. Amin M, Dill -Russell P, Manisali M, Lee R, Sinton I. Facial fractures and submental tracheal intubation. Anaesthesia. 2002 Dec; 57 (12): 11951199.

3. Chandu A, Smith AC, Gebert R. Submental intubation: an alternative to short term tracheostomy. Anaesth Intensive Care. 2000; 28: 193-195.

4. Johnson TR. Submental versus tracheostomy. Br J Anaesth. 2002; 89: 344-345.

5. Paetkau DJ, Stranc MF, Ong BY. Submental orotracheal intubation for maxillofacial surgery. Anesthesiology. 2000; 92: 912.

6. Anuradha Navaneetham, S. Vinod Thangaswamy, Naveen Rao. Submental intubation: our experience. J Maxillofac Oral Surg. 2010 March; 9 (1): 64-67

7. Caubi AF1, Vasconcelos BC, Vasconcellos RJ, de Morais HH, Rocha NS. Submental intubation in oral maxillofacial surgery: review of the literature and analysis of 13 cases. Med Oral Patol Oral Cir Bucal. 2008 Mar 1; 13 (3)

8. Jundt JS, Cattano D, Hagberg CA, Wilson JW. Submental intubation: a literature review. Int J Oral Maxillofac Surg. 2011; 10: 1016-25.
9. Meyer C, Valfrey J, Kjartansdottir T, Wilk A, Barriere P. Indication for and technical refinements of submental intubation in oral and maxillofacial surgery. J Craniomaxillofac Surg. 2003; 31: 383-8.

10. Herna'ndez Altemir F. The submental route for endotracheal intubation. A new technique. J Maxillofac Surg. 1986; 14: 64-65.

11. Biglioli F, Mortini P, Goisis M, Bardazzi A, Boari N. Submental orotracheal intubation. An alternative to tracheotomy in transfacial cranial base surgery. Skull Base. 2003; 13: 189-96.

12. Chandu A, Witherow H, Stewart A. Submental intubation in orthognathic surgery: initial experience. Br J Oral Maxillofac Surg. 2008; 46: 561-3.

13. Nyarady Z, Sari F, Olasz L, Nyarady J. Submental endotracheal intubation in concurrent orthognatic surgery: a technical note. J Craniomaxillofac Surg. 2006; 34: 362-5.

14. Eipe N, Neuhoefer ES, La Rosee G, Choudhrie H, Samman N, Kreusch T. Submental intubation for cancrum oris: a case report. Paediatr Anaesth. 2005; 15: 1009-12.

15. Meyer C, Valfrey J, Kjartansdottir T, Wilk A, Barrière $P$. Indication for and technical refinements of submental intubation in oral and maxillofacial surgery. J Craniomaxillofac Surg. 2003 Dec; 31 (6): 383-388

16. Sharma RK, Tuli VF P, Cyriac C, Parashar A, Makkar S. Submental tracheal intubation in oromaxillofacial surgery. Indian J Plast Surg. 2008; 41: 15-19. 